\title{
TAMAN SATWA KOTA PONTIANAK
}

\author{
Wari Walingga $^{1}$, Tri Wibowo Caesariadi ${ }^{2}$, Yudi Purnomo ${ }^{3}$ \\ ${ }^{1}$ Mahasiswa, Program Studi Arsitektur, Fakultas Teknik, Universitas Tanjungpura. \\ wwalingga@gmail.com \\ ${ }^{2}$ Program Studi Arsitektur, Fakultas Teknik, Universitas Tanjungpura \\ ${ }^{3}$ Program Studi Arsitektur, Fakultas Teknik, Universitas Tanjungpura
}

Naskah diajukan pada: 21 Januari 2021

Naskah revisi akhir diterima pada: 21 Februari 2021

\begin{abstract}
Abstrak
Taman Satwa merupakan salah satu bentuk Lembaga konservasi ex-situ yang berfungsi sebagai wadah melestarikan fauna di luar habitat aslinya yang bersifat publik. Selain memiliki fungsi konservasi Taman Satwa juga memiliki fungsi rekreasi, edukasi dan penelitian. Perencanaan Taman Satwa di Kota Pontianak juga merupakan salah satu bentuk penetapan dan pengelolaan kawasan lindung yang mampu memperhatikan kelestarian dukungan fungsi lingkungan hidup di Kota Pontianak. Artikel ini bertujuan menjelaskan proses perancangan Taman Satwa sebagai pusat rekreasi dan wisata tentang pengenalan satwa asli Kalimantan Barat. Tema atau Konsep perancangan yang direncanakan adalah pertimbangan prilaku hidup satwa tanpa mengurangi kenyamanan dari sisi pengunjung. Perancangan ini memberikan batas antara zona pengujung dan zona satwa, serta penempatan zona servis pengelola yang terpisah dengan zona pengunjung namun tetap dapat terhubung dengan setiap kandang satwa. Dalam desain yang dilakukan, kandang untuk habitat hewan menggunakan struktur membran untuk spesies primata dan struktur bentang lebar untuk membentuk kandang kandang untuk spesies aves.
\end{abstract}

Kata-kata kunci: Taman Satwa, Konservasi ex-situ, satwa, pengunjung

\begin{abstract}
Animal Park is a form of ex-situ conservation institution that functions as a forum for preserving fauna outside of their natural habitat which is public. Besides having a conservation function, the Animal Park also has recreational, educational and research functions. Animal Park Planning in Pontianak City is also a form of designation and management of protected areas that are able to pay attention to the sustainability of supporting environmental functions in Pontianak City. This article aims to explain the process of designing a Wildlife Park as a recreation and tourism center regarding the introduction of native animals of West Kalimantan. The theme or design concept that is planned is the consideration of the animal's life behavior without reducing the comfort from the visitor's side. This design provides a boundary between the end zone and the animal zone, as well as the placement of a management service zone that is separate from the visitor zone but can still be connected to each animal enclosure. In the design carried out, the enclosure for the animal habitat uses a membrane structure for primate species and a wide-span structure to form an aviary enclosure for aves species.
\end{abstract}

Keywords: Animal Park, ex-situ conservation, animals, visitors

\section{Pendahuluan}

Kawasan Konservasi merupakan suatu tempat atau wadah yang melakukan upaya perawatan dan pengembangbiakan berbagai jenis satwa berdasarkan etika dan kaidah kesejahteraan satwa dalam rangka membentuk dan mengembangkan habitat baru, sebagai sarana perlindungan dan pelestarian jenis melalui kegiatan penyelamatan, rehabilitasi dan reintroduksi alam dan dimanfaatkan sebagai sarana pendidikan, penelitian, pengembangan ilmu pengetahuan dan teknologi serta sarana rekreasi yang sehat. 
Sebagai salah satu Provinsi yang ada di Indonesia, Provinsi Kalimantan Barat memiliki beberapa Kawasan Konservasi yang berfungsi menjaga keberlangsungan hidup satwa yang ada di habitat aslinya (in-situ). Berdasarkan Peraturan Daerah Kota Pontianak No. 2 Tahun 2013 Tentang Rencana Tata Ruang Wilayah Kota Pontianak Tahun 2013-2033 Bab III Bagian Kedua Kebijakan Penataan Ruang Wilayah Kota Pasal 4, poin e yang berbunyi penetapan dan pengelolaan kawasan lindung yang mampu memperhatikan kelestarian dukungan fungsi lingkungan hidup.

Selain itu juga terdapat pada Bab III Bagian Ketiga Strategi Penataan Ruang Wilayah Kota Pasal 5 ayat 5 Tentang Strategi penetapan dan pengelolaan kawasan lindung yang mampu memperhatikan kelestarian dukungan fungsi lingkungan hidup, meliputi mengembangkan ruang terbuka hijau (RTH) kota paling sedikit 30\% dari luas wilayah kota, menetapkan kawasan berfungsi lindung, mengembalikan fungsi kawasan lindung yang telah beralih fungsi, mempertahankan dan merevitalisasi kawasan cagar budaya dan mengembangkan kerjasama dengan Pemerintahan Kabupaten Kubu Raya dalam rangka meningkatkan fungsi lindung.

Kawasan Konservasi yang direncanakan tidak terlepas dari strategi pengembangan fungsi dan peningkatan peran dari pusat-pusat kegiatan dan kawasan strategis baik dalam lingkup internal maupun eksternal dengan memacu perkembangan Kota Pontianak dan kawasan perkotaan di sekitarnya menjadi Kawasan Metropolitan Pontianak seperti yang tercantum di dalam Peraturan Daerah Provinsi Kalimantan Barat No. 10 Tahun 2014 Tentang Rencana Tata Ruang Wilayah Provinsi Kalimantan Barat Tahun 2014-2034 Bab III Rencana Struktur Ruang Wilayah Provinsi Bagian Kedua Rencana Pusat-pusat Kegiatan Pasal 13 huruf A.

Kawasan konservasi Taman Satwa merupakan salah satu Kawasan Konservasi yang bersifat publik dan dapat menampung satwa khas Kalimantan Barat dalam keadaan hidup. Selain itu, keberadaan taman satwa dapat memberikan inovasi keunikan obyek wisatadi Kota Pontianak. Taman Satwa dapat dimanfaatkan sebagai ruang terbuka hijau atau kawasan lindung yang dapat menampung resapan air kota untuk mengurangi resiko bencana alam yang berupa banjir pada saat musim hujan yang mengakibatkan air meluap ke jalan sehingga mengganggu transportasi dan kegiatan masyarakat, serta dapat dimanfaatkan bagi produsen oksigen $\left(\mathrm{O}^{2}\right)$ bagi Kota Pontianak dan sekitarnya.

\section{Kajian Pustaka}

Berdasarkan Peraturan Menteri Kehutanan Republik Indonesia No. P.31/Menhut-II/2012 Tentang Lembaga Konservasi Bab 1 Pasal 2 Taman Satwa sebagai salah satu Lembaga Konservasi mempunyai fungsi utama pengembangbiakan terkontrol dan penyelamatan tumbuhan dan satwa dengan tetap mempertahankan kemurnian jenisnya. Selain itu, Lembaga konservasi juga mempunyai fungsi sebagai tempat pendidikan, peragaan, penitipan sementara, sumber indukan dan cadangan genetik untuk mendukung populasi in-situ, sarana rekreasi yang sehat serta penelitian dan pengembangan ilmu pengetahuan.

Pada perancangan Taman Satwa pertimbangan lingkungan tempat hidup satwa harus disesuaikan dengan kebutuhan setiap satwa. Tempat hidup mereka harus termasuk tempat berteduh dari basahnya hujan, dari panas matahari, dingin dan tempat bernaung yang layak bagi satwa. Berdasarkan Peraturan Menteri Kehutanan Republik Indonesia No. P.31/Menhut-II/2012 Tentang Lembaga Konservasi Bab 2 Pasal 11 Taman Satwa memiliki kriteria memiliki jenis satwa yang dikoleksi sekurang-kurangnya 2 (dua) kelas taksa, memiliki luas areal sekurang-kurangnya 2 (dua) hektar, memiliki jenis satwa yang dilindungi, satwa yang tidak dilindungi dan/atau satwa asing, memiliki sarana pemeliharaan dan perawatan satwa, memiliki fasilitas kesehatan, memiliki fasilitas pelayanan pengunjung, memiliki tenaga kerja permanen sesuai bidang keahliannya, memiliki fasilitas kantor pengelola, dan memiliki fasilitas pengelolaan limbah.

Perancangan Taman Satwa yang ini menggunakan Design Guidelines for Zoos (Mehta, 2018) sebagai panduan dalam perancangan Taman Satwa terkait habitat, ekosistem dan fasilitas yang 
disediakan untuk satwa yang akan tinggal di dalam Taman Satwa berupa ruang, elemen, vegetasi, fasilitas untuk Satwa.

\section{Metode}

Metode perancangan Taman Satwa Kota Pontianakmengacu kepada metode menurut J.C. jones yang terdiri dari enam tahap perancangan yaitu gagasan, informasi, analisa, sintesis, evaluasi, dan opltimalisasi (Nuraini, 2010). Pada tahap gagasan dimulai dengan penentuan judul "Taman Satwa Kota Pontianak", pencarian ide dan gagasan yang melatarbelakangi perancangan, kemudian perumusan masalah, tujuan sasaran, manfaat, dan lingkup tugas. Pada tahap informasi, mencari dan memaparkan data. Data terdiri dari data primer dan skunder. Data primer merupakan data tapak perancangan Taman Satwa Kota Pontianak, sedangkan data skunder merupakan teori yang diperoleh dari literatur tentang Taman Satwa. Tahapan analisa, merupakan proses analisa internal, eksternal, bentuk, struktur, utilitas dan fisika bangunan pada perancangan. Tahap Sintesis merupakan perumusan konsep perancangan dari hasil analisa yang telah dilakukan. Tahap evaluasi merupakan rancangan skematik pada perancangan Taman Satwa. Tahap optimalisasi merupakan pengaplikasian dan pengoptimalisasi konsep perancangan terhadap gambar masterplan, denah, tampak, potongan dan lain-lain.

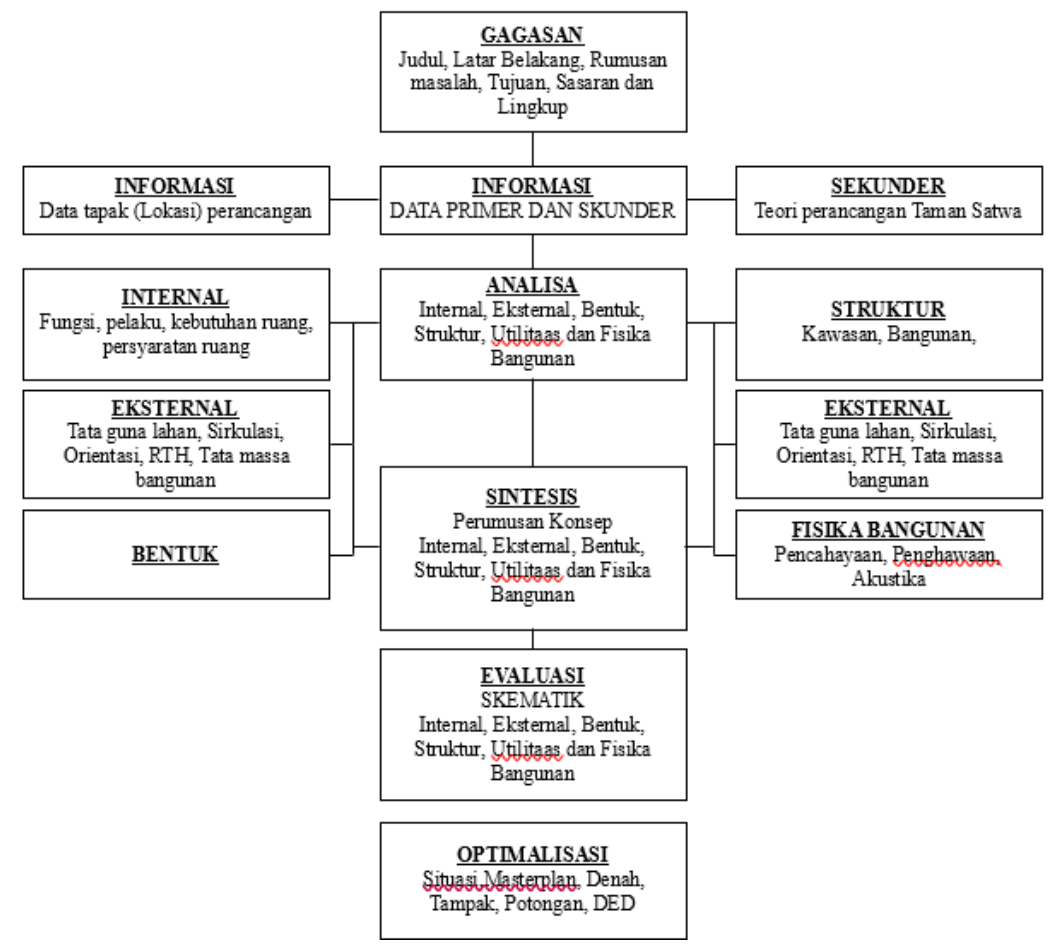

Gambar 1. Proses Perancangan Taman Satwa Kota Pontianak Sumber: Penulis, 2020

\section{Hasil dan Pembahasan}

\section{Landasan Konseptual}

Landasan Konseptual dalam perancangan ini bertujuan untuk mendapatkan alternatif desain yang nantinya akan menghasilkan analisis yang berfungsi untuk memberikan penilaian dan perbandingan konsep perancangan.

Satwa yang akan di pelihara merupakan satwa endemik Kalimantan Barat yang terlampir dalam PERMENLHK No. P.20/ MENLHK/ SETJEN/ KUM.1/ 6/ 2018 Tentang Jenis Tumbuhan dan Satwa Yang Dilindungi. Selain itu pertimbangan status konservasi satwa juga terdapat di IUCN Red List (2020) dan CITES (2020). 


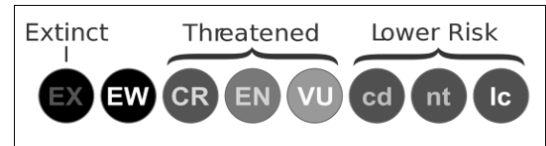

\section{Gambar 2. Diagram Status Konservasi Satwa Sumber: IUCN Red List, 1984}

Gambar 1 menunjukkan diagram status konservasi satwa yang dikeluarkan oleh IUCN Red List pada tahun 1984. Extinct (EX: Punah), Extinct In The Wild (EW: Punah Alam Liar), Critically Endangered(CR: Kritis), Endangered(EN: Terancam), Vulnerable (VU: Rentan), Near Threatened (NT: Hampir Terancam), Least Concern (LC: Risiko Rendah), Data Deficient (DD: Informasi Kurang), Not Evaluated (NE: Belum Evaluasi). Sedangkan CITES merupakan sebuah perjanjian internasional yang beranggotakan pemerintahan negara-negara di dunia untuk memastikan perdagangan spesies hewan dan tumbuhan tidak menyebabkan ancaman bagi kelangsungan hidup suatu spesies. CITES memiliki 3 kategori status konservasi yang diatur perdagangannya, Apendix 1 Meliputi flora dan fauna yang terancam punah, Apendix 2 Meliputi spesies yang tidak selalu terancam kepunahannya, Apendix 3 Meliputi spesies yang dilindungi oleh setidaknya 1 negara.

Besaran ruang dalam perancangan ini diperoleh berdasarkan standar dimensi Neufert (2002) dan Design Guidelines for Zoos (Mehta, 2018). Berdasarkan hasil Analisa diperoleh total besaran ruang yang dibutuhkan dalam Perancangan Taman Satwa adalah 28070,54 m².

Tabel 1. Total Analisis Besaran Ruang

\begin{tabular}{|c|c|}
\hline \multicolumn{2}{|c|}{ Total Besaran Ruang } \\
\hline Pelaku & Besaran \\
\hline Pengunjung & 2274,08 \\
\hline Pengelola & 4715,66 \\
\hline Reptil & 2620 \\
\hline Mamalia & 16000,8 \\
\hline Aves & 2460 \\
\hline Total & 28070,54 \\
\hline
\end{tabular}

Lokasi Perancangan terletak pada Jalan Panca Bhakti. Pontianak Utara, Kota Pontianak, Kalimantan Barat. Adapun pertimbangan dari pemilihan lokasi ini berdasarkan penjabaran dari kelebihan serta kekurangan dari lokasi perancangan. Kekurangan pada lokasi perancangan kondisi Jalan sebagian tidak memiliki perkerasan sehingga kesulitan untuk diakses, berada dekat dengan perkebunan milik masyarakat, dan lokasi site merupakan lahan milik masyarakat.

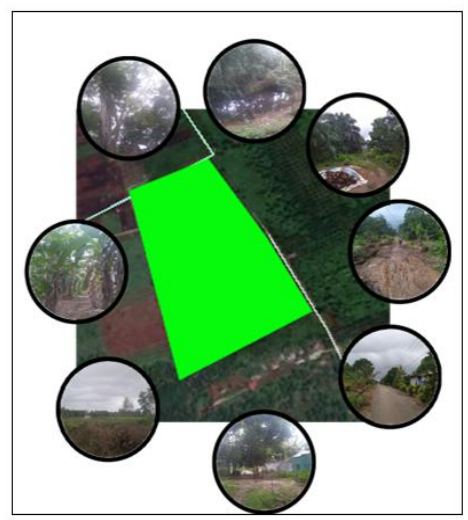

Gambar 3. Lokasi Perancangan

Sumber: Penulis, 2020 
Kelebihan pada lokasi site memiliki kondisi lingkungan yang cukup baik, Jauh dari permukiman penduduk, di dalam site masih terdapat vegetasi alami, terdapat bagian yang berkontur sehingga dapat meningkatkan potensi ruang yang dimanfaatkan sebagai Zona Satwa, kondisi jalan sepi dan hanya dilalui oleh kendaraan milik masyarakat, berada pada batas Kota Pontianak dan Kabupaten Mempawah sehingga dapat dilakukan kerja sama antar pemerintah daerah dalam pelaksanaannya, dan lokasi merupakan peruntukan Ruang Terbuka Hijau berdasarkan RTRW Kota Pontianak 2013-2033.

Analisis peletakan didapatkan berdasarkan peraturan yang ditetapkan oleh Pemerintah Daerah, misalnya tentang tata guna lahan yang difungsikan sebagai kawasan pemerintahan segmen satu ataupun tentang koefisien dasar bangunan yang dapat menentukan seberapa besar bangunan dapat dibangun di atas tanah, garis sempadan bangunan (GSB).

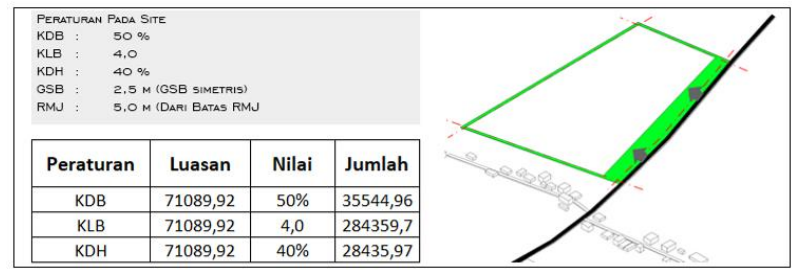

Gambar 4. Analisa Perletakan

Sumber: Penulis, 2020

Perletakan massa bangunan berada di tengah kawasan, sedikit jauh dari area jalan agar dapat meminimalisir tingkat kebisingan dari arah jalan. Selain itu, perletakan bangunan diletakkan di bagian tengah kawasan agar bagian sisa yang berbatasan dengan lahan di luar kawasan dapat ditanami vegetasi yang berfungsi sebagai pembatas kawasan dengan lahan sekitar.

Analisis orientasi Kawasan dilakukan untuk mengetahui arah hadap setiap bangunan di dalam kawasan perancangan. Gambar 3 menunjukkan arah matahari dan angin pada kawasan. Berdasarkan arah matahari dan angin pada sekitar kawasan dapat ditentukan orientasi hadap kawasan menghadap ke arah timur kawasan untuk memaksimalkan penghawaan dan pencahayaan alami. Selain itu orientasi hadap timur juga berdasarkan pertimbangan jalur sirkulasi utama menuju kawasan yang terletak pada bagian timur.

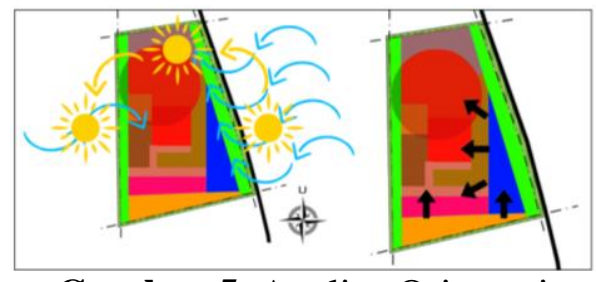

Gambar 5. Analisa Orientasi

Sumber: Penulis, 2020

Gambar 4 menunjukkan orientasi di dalam kawasan. Zona pengelola dan servis berorientasi kepada zona satwa dan zona pengunjung, orientasi ini bertujuan mempermudah akses servis pada zona satwa dan zona pengunjung. Sedangkan pada zona pengunjung berorientasi kepada zona satwa yang tinggal di dalam kawasan untuk mempermudah pengunjung mengakses zona satwa.

Analisa sirkulasi diperlukan untuk mengetahui alur akses pada lingkungan area bangunan berdasarkan pertimbangan tingkat kemacetan maupun aksesibilitas pencapaian. 


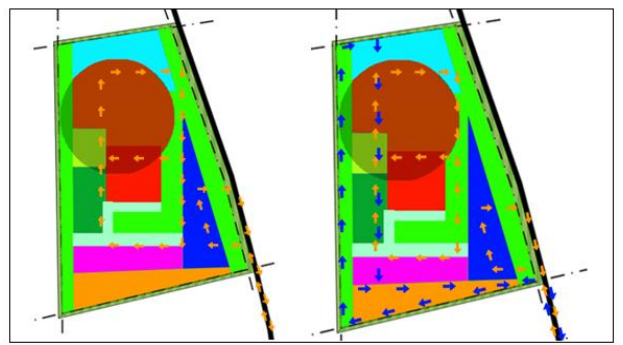

Gambar 6. Analisa Sirkulasi Pengunjung dan Pengelola

Sumber: Penulis, 2020

Gambar 5 menunjukkan Analisa sirkulasi bagi fungsi pengunjung. Jalur sirkulasi masuk pengunjung ke dalam kawasan melalui Jalan Panca Bhakti Pontianak Utara. Pada jalur sirkulasi masuk dan keluar pengunjung pada kawasan menggunakan jalur sirkulasi satu arah. Sedangkan jalur masuk dan keluar dari kawasan fungsi pengelola dan servis dipisahkan dengan jalur sirkulasi masuk dan keluar pengunjung. Pemisahan ini dilakukan agar kendaraan pengunjung tidak masuk ke dalam zona pengelola dan zona servis. Selain itu, gambar 5 menunjukkan pemisahan jalur sirkulasi fungsi pengelola dan servis di dalam kawasan dipisahkan dengan jalur sirkulasi pengunjung.

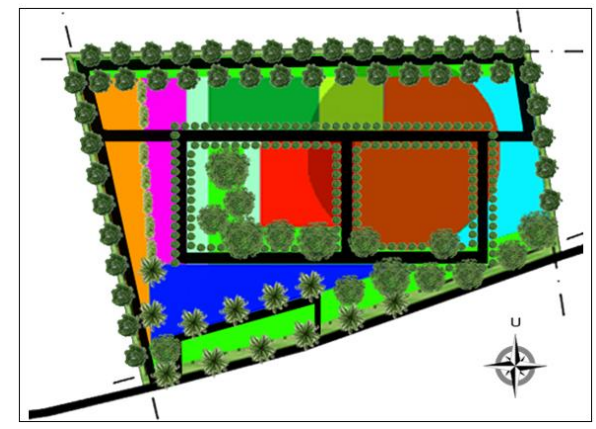

Gambar 7. Analisa Vegetasi

Sumber: Penulis, 2020

Analisis jenis vegetasi yang akan digunakan dalam perancangan berdasarkan pada pertimbangan arsitektur lingkungan. Pada analisa vegetasi ini selain beberapa vegetasi yang telah di analisa juga dapat memanfaatkan beberapa jenis vegetasi lainnya. Vegetasi yang direncanakan juga harus memiliki manfaat bagi satwa yang tinggal di dalam kawasan Taman Satwa contohnya tanaman buah-buahan yang dapat sebagai makanan satwa.

Analisis zoning dilakukan agar dapat mengetahui sifat-sifat serta fungsi ruang dengan pembagian zona ruang berdasarkan beberapa pertimbangan.

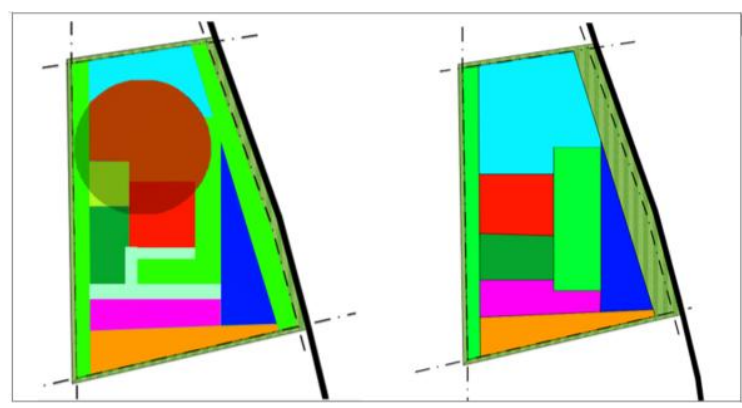

Gambar 8. Hasil Analisa Zonasi

Sumber: Penulis, 2020 
Berdasarkan pertimbangan arah matahari, angin dan kebisingan pada kawasan, maka zonasi pada kawasan dibagi menjadi penempatan zona servis dan zona pengelola ditunjukkan dengan warna orange, zona pengunjung ditunjukkan dengan warna biru, zona satwa reptil ditunjukkan dengan warna merah jambu, zona satwa aves ditunjukkan dengan warna hijau tua, zona satwa primata ditunjukkan dengan warna coklat, zona satwa mamalia karnivora ditunjukkan dengan warna merah, zona warna biru muda satwa mamalia herbivora, dan zona hijau muda merupakan zona penghijauan di dalam kawasan.

Pada perancangan Taman Satwa perkerasan yang dilakukan difokuskan pada perkerasan jalur sirkulasi yang terdapat di dalam kawasan. Pemanfaatan perkerasan aspal dinilai cocok dikarenakan pertimbangan pada jalur sirkulasi ini akan dilalui oleh kendaraan servis dan kendaraan pengunjung di dalam kawasan. Sedangkan jalur sirkulasi di dalam kawasan memanfaatkan grass block sebagai material perkerasan. Grass block di pilih karena pertimbangan curah hujan yang cukup tinggi di Kota Pontianak sehingga air hujan yang jatuh dapat terserap dan tidak terjadi genangan.

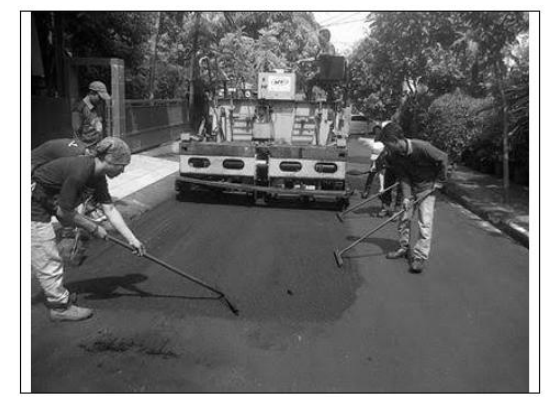

Gambar 9. Perkerasan Aspal Pada Kawasan

Sumber: Anwar, 2018

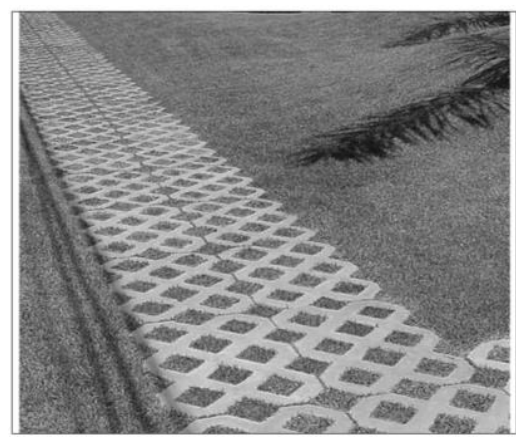

Gambar 10. Perkerasan Grass Block Pada Kawasan

Sumber: Rani, 2016

Di dalam perancangan Taman Satwa dinding penahan tanah berfungsi sebagai penahan pada bagian sisi kolam dan pada bagian sisi jalur sirkulasi pada zona berkontur di dalam kawasan. Pada perancangan dinding turap dimanfaatkan karena konstruksinya di perkeras dengan beton bertulang untuk dapat menahan tekanan air hujan dan beban pengunjung yang melintasi jalur sirkulasi pada zona berkontur. Selain itu pemanfaatan dinding turap juga dapat menahan bagian sisi kolam dari abrasi dan erosi. 


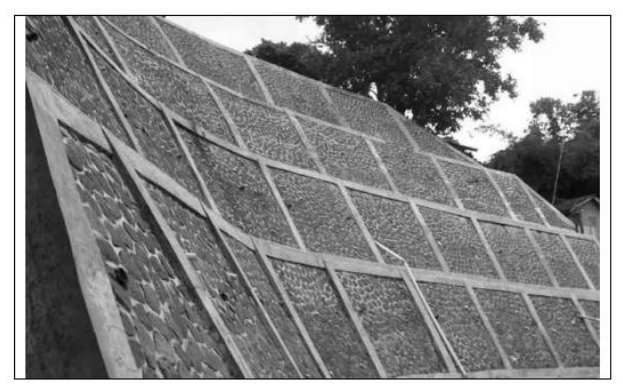

Gambar 11. Dinding Turap

Sumber: Ramadhan, 2019

Utilitas Kawasan bertujuan untuk mendukung dan memberikan kenyamanan dan keamanan bagi kawasan perancangan maupun satwa yang tinggal di dalam kawasan. Sistem distribusi air bersih kawasan perancangan memanfaatkan air hujan yang di tampung pada kolam yang disediakan.

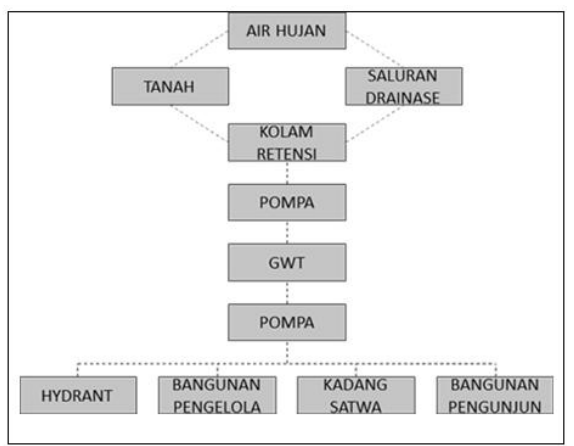

Gambar 12. Diagram Alir Distribusi Air Bersih

Sumber: Penulis, 2020

Gambar 11 menunjukkan pemanfaatan air hujan sebagai sumber air bersih di dalam kawasan perancangan. Air hujan yang jatuh akan disalurkan melalui saluran drainase yang ada pada kawasan menuju kolam retensi. Air hujan yang di tampung oleh kolam retensi yang disediakan setelah mengalami pengendapan kemudian akan disalurkan melalui pompa menuju Ground Water Tank (GWT). Lalu disalurkan menggunakan pompa menuju bangunan pengelola dan servis, seluruh kandang satwa, dan bangunan pengunjung.

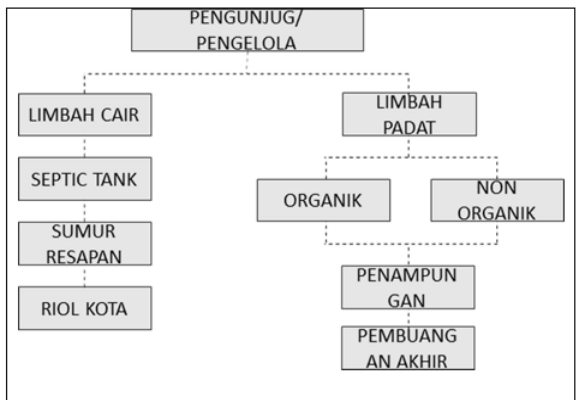

\section{Gambar 13. Diagram Alir Distribusi Air Kotor}

Sumber: Penulis, 2020

Gambar 12 menunjukkan bagaimana pengolahan limbah yang ada di dalam kawasan menuju pembuangan akhir. Sistem pengolahan limbah cair yang dihasilkan oleh pihak pengelola dan pengunjung ditampung pada Septictank sedangkan limbah cair yang dihasilkan kemudian akan disalurkan menuju sumur resapan, air hasil endapan dapat di salurkan menuju saluran drainase yang 
terdapat di luar kawasan atau dimanfaatkan untuk menyiram tanaman. Sedangkan untuk limbah padat di bagi menjadi dua yaitu limbah organik dan limbah non organik di tampung pada tempat penampungan terpisah yang tersebar di dalam kawasan.

Perancangan Taman Satwa menggunakan dua jenis sistem pemadam kebakaran. Pemanfaatan hydrant ditempatkan dengan jarak setiap 35 meter, untuk distribusi air menuju setiap box hydrant menggunakan pipa besi yang ditanam dengan kedalaman tertentu dan menggunakan pompa untuk mendistribusikan air dari Ground Water Tank (GWT) atau kolam penampungan air.

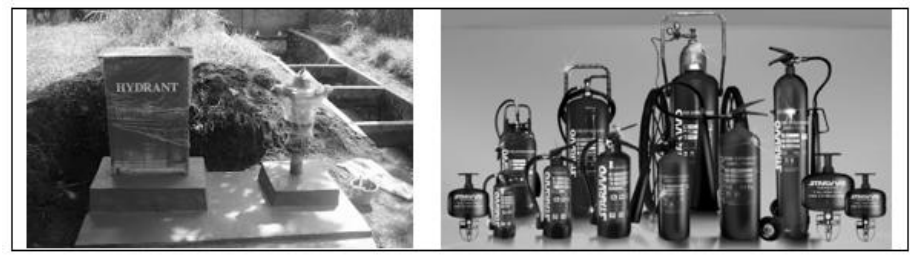

Gambar 14. Sistem Keamanan Kebakaran Sumber: BSP Guard, 2017

Pada bangunan yang terdapat di dalam kawasan perancangan dilengkapi oleh APAR. Pemanfaatan APAR pada bangunan ini ditempatkan setiap jarak 20 meter di dalam bangunan peletakannya juga harus pada tempat yang mudah di lihat dan dijangkau.

\section{Konsep Perancangan}

Konsep perancangan Taman Satwa sebagai sarana konservasi sekaligus sebagai sarana rekreasi/wisata, edukasi, penelitian bagi masyarakat dan Lembaga terkait. Pola sirkulasi yang diterapkan untuk fungsi pengunjung saling terhubung antara satu dengan yang lainnya pada setiap zona satwa dan terdapat pemisahan pada sirkulasi pengunjung dan sirkulasi pengelola.

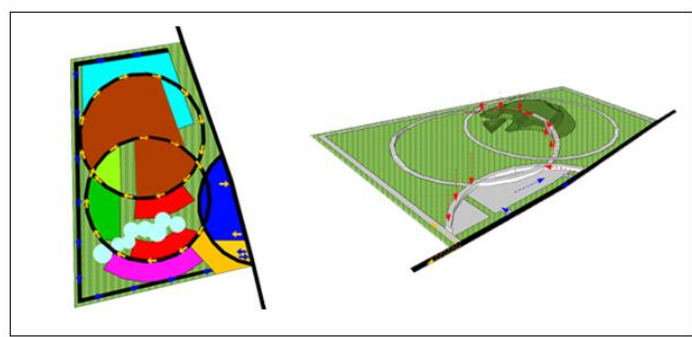

Gambar 15. Konsep Sirkulasi Pengunjung \& Pengelola Sumber: Penulis, 2020 


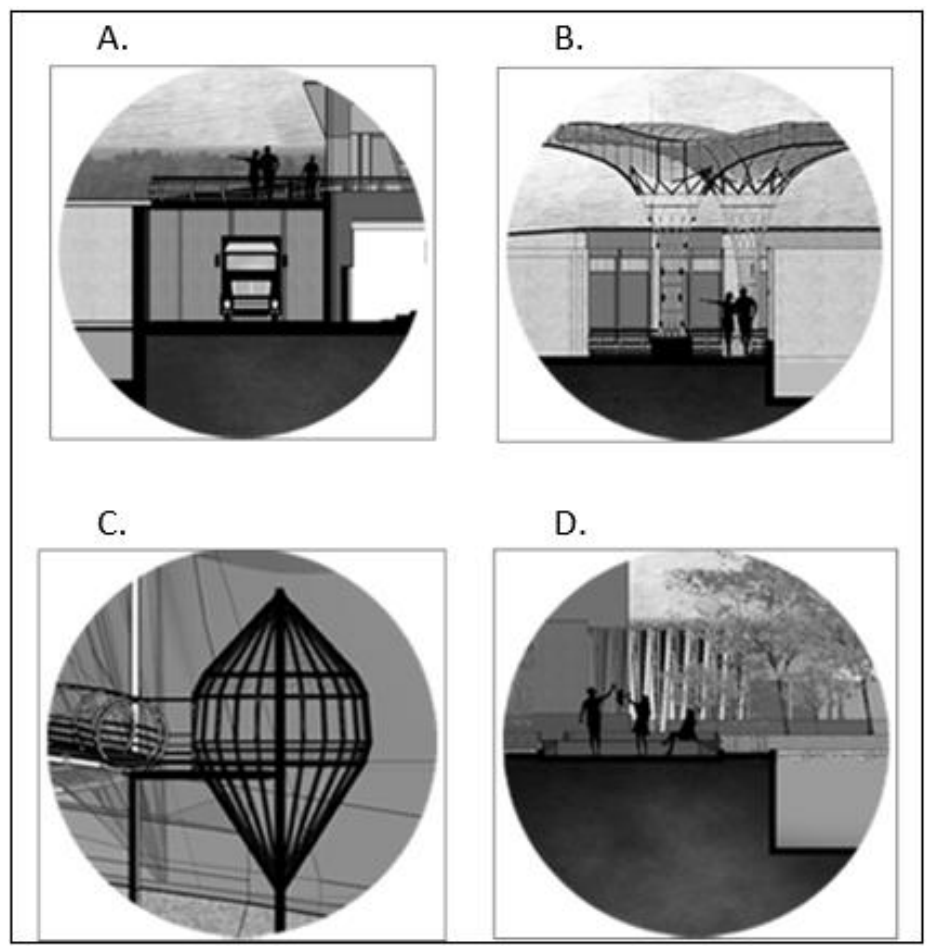

Gambar 16. Konsep Didalam Kawasan

Sumber: Penulis, 2020

Gambar A perubahan elevasi pada jalur sirkulasi pengunjung diakibatkan topografi alami pada kawasan perubahan elevasi ini dapat dimanfaatkan sebagai pemisahan dengan jalur sirkulasi fungsi pengelola, hal ini mempertimbangkan kemudahan akses bagi pengelola menuju kandang satwa yang terdapat pada bagian berkontur dan dekat dengan zona pengunjung. Gambar B menunjukkan pergola pada kawasan, pemanfaatan pergola di kawasan diletakkan pada zona bangunan pengunjung dan pada tengah jalur sirkulasi pengunjung. Pemanfaatan pergola berfungsi sebagai penyaring cahaya matahari berlebihan dan menjadi peneduh pada saat siang hari. Gambar $\mathrm{C}$ menunjukkan gazebo pada zona berkontur yang terdapat pada kawasan. Pada gazebo memanfaatkan gertak sebagai penghubung setiap gazebo yang ada. Gambar D menunjukkan taman yang terhubung dengan kolam retensi kawasan. Taman yang direncanakan berada dekat dengan bangunan pengunjung di dalam kawasan. Taman ini berfungsi sebagai pemecah sirkulasi pengunjung di dalam kawasan.

Pemanfaatan struktur membran sebagai lapisan penutup zona berkontur bertujuan agar kawasan dapat terlihat lebih alami dan dapat memberikan kesan natural bagi pengunjung saat berada di dalam kandang (Gambar 16 A). Selain itu juga bertujuan memberikan ruang yang lebih luas agar satwa dapat menunjukkan perilaku alami satwa. Struktur utama yang dimanfaatkan sebagai penopang lapisan penutup pada bagian atas menggunakan material baja, dengan pondasi telapak pada bagian bawah, sedangkan lapisan penutup menggunakan stainless steel zoo wire mesh yang dihubungkan dengan kabel seling untuk menopang lapisan penutup. 


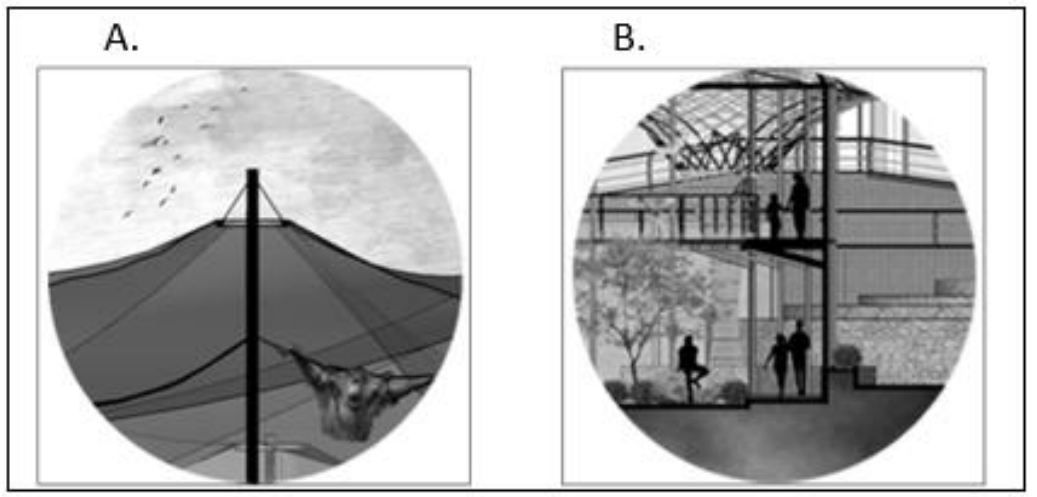

Gambar 17. Konsep Struktur Kawasan

Sumber: Penulis, 2020

Kandang aviary, memanfaatkan struktur baja bentang lebar (Gambar 16 B). Pemanfaatan struktur baja bentang lebar guna menghilangkan kolom pada kandang dan memaksimalkan ruang gerak bagi satwa aves. Struktur bagian bawah kandang memanfaatkan pondasi menerus untuk memaksimalkan penyaluran beban yang ditopang. Bagian penutup kandang dilapisi dengan stainless steel zoo wire mesh untuk memaksimalkan pencahayaan dan penghawaan alami secara maksimal. Jalur sirkulasi di dalam kandang bagian lantai dasar memanfaatkan grass block sebagai perkerasan. Sedangkan pada bagian lantai pada bagian atas memanfaatkan struktur utama kandang dengan penambahan cantilever untuk menopang beban diatasnya yang dihubungkan dengan ramp.

\section{Hasil Perancangan}

Berikut ini merupakan hasil gambar perancangan Taman Satwa di Kota Pontianak yang terletak pada Jl Panca Bhakti Kecamatan Pontianak Utara.

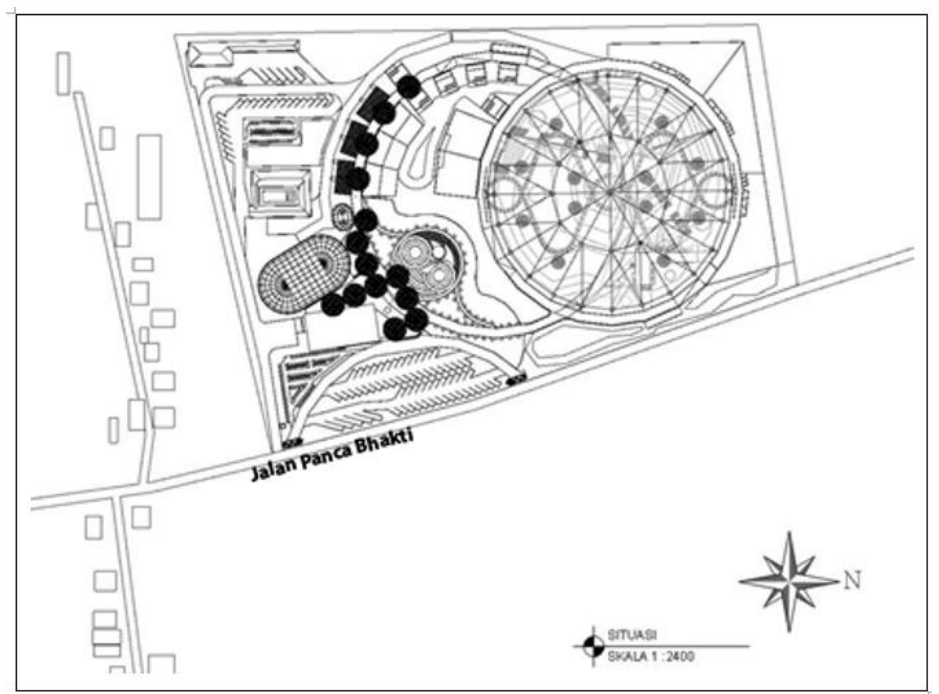

Gambar 18. Situasi Taman Satwa

Sumber: Penulis, 2020 


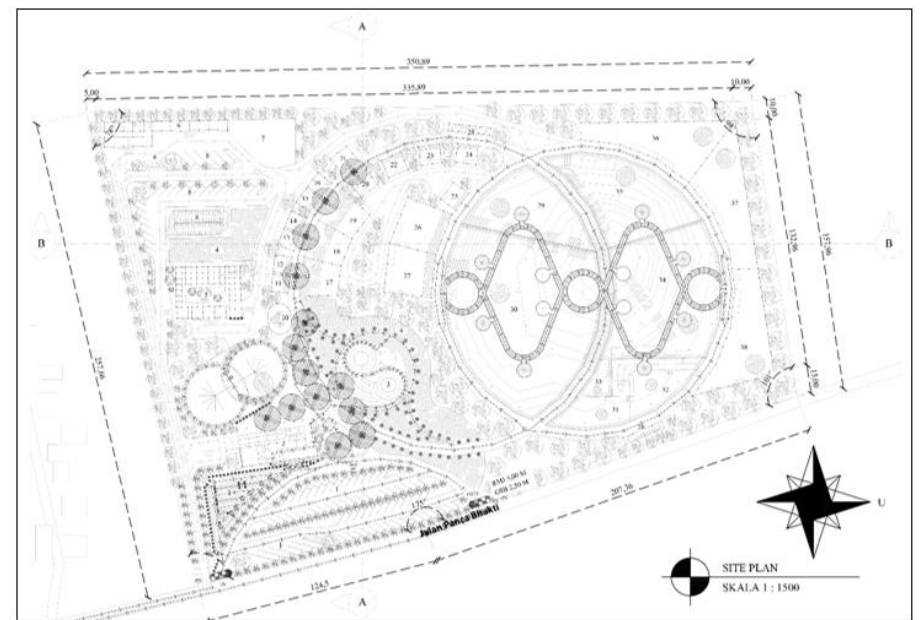

Gambar 19. Site Plan Taman Satwa

Sumber: Penulis, 2020

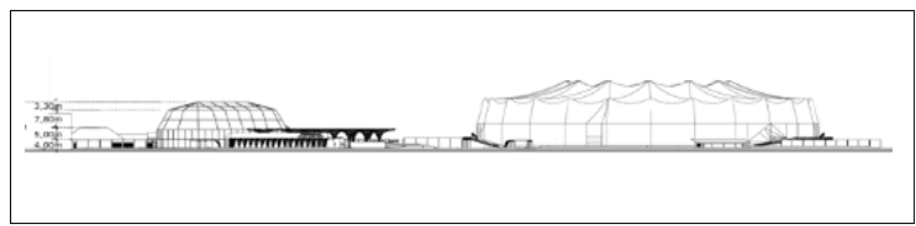

Gambar 20. Tampak Depan Taman Satwa Sumber: Penulis, 2020

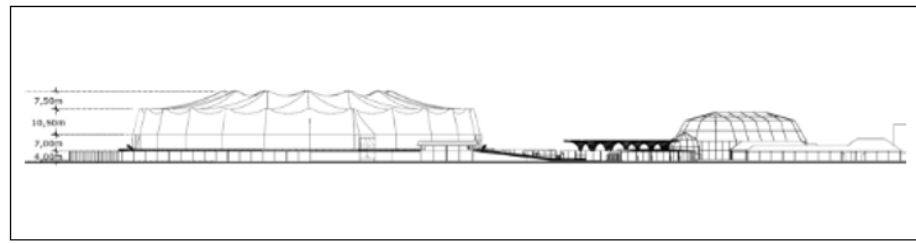

Gambar 21. Tampak Belakang Taman Satwa Sumber: Penulis, 2020

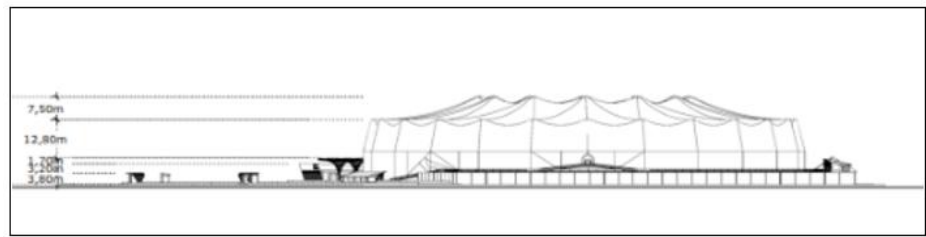

Gambar 22. Tampak Kiri Taman Satwa Sumber: Penulis, 2020

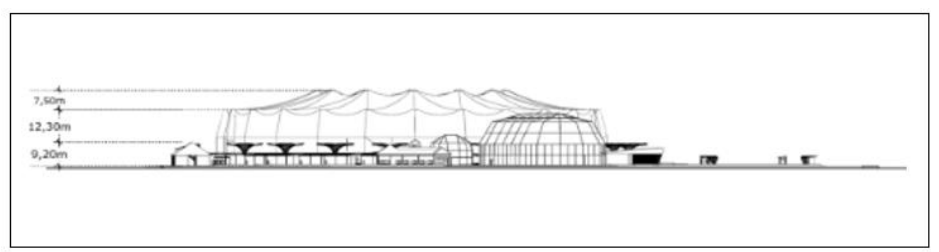

Gambar 23.Tampak Kanan Taman Satwa Sumber: Penulis, 2020 


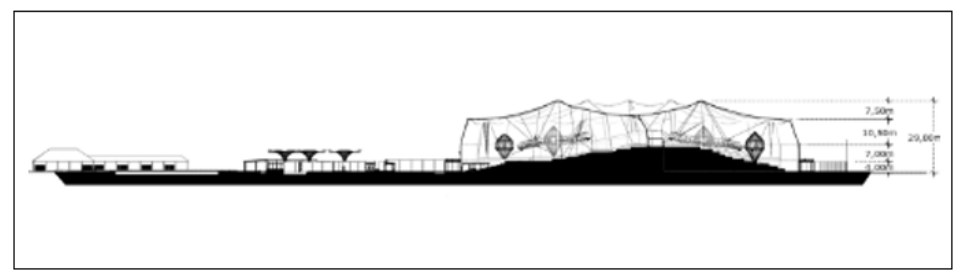

Gambar 24. Potongan Memanjang Kawasan Taman Satwa Sumber: Penulis, 2020

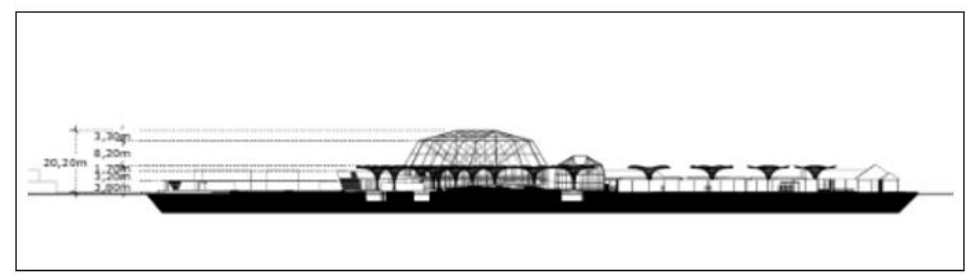

Gambar 25. Potongan Melintang Kawasan Taman Satwa Sumber: Penulis, 2020

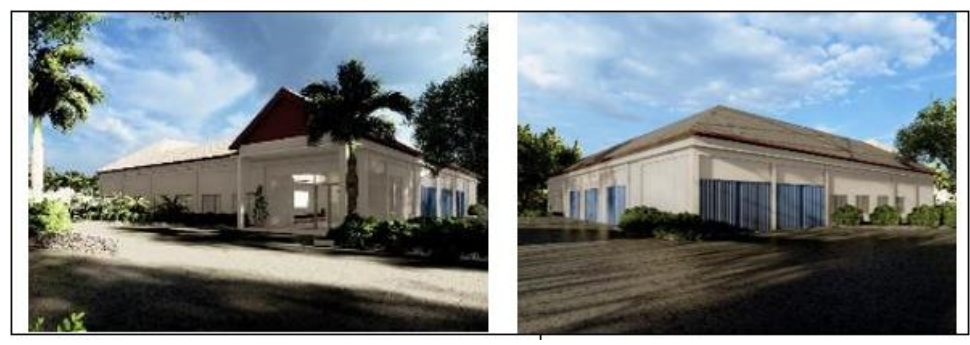

Gambar 26. Suasana Eksterior Bangunan Pengelola Sumber: Penulis, 2020

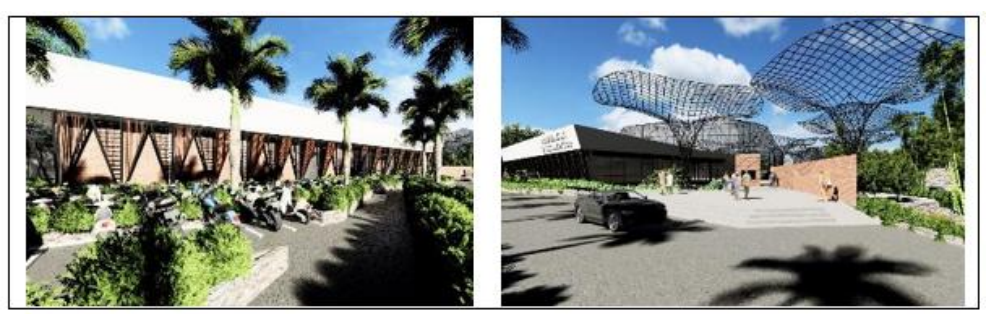

Gambar 27. Suasana Eksterior Bangunan Pengunjung Sumber: Penulis, 2020

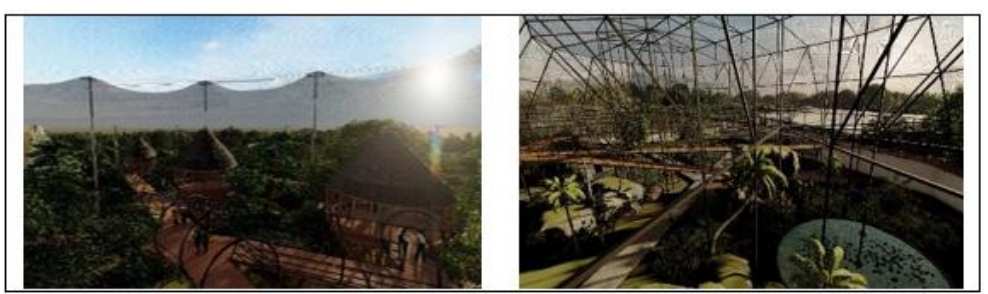

Gambar 28. Suasana Interior Kandang Sumber: Penulis, 2020 


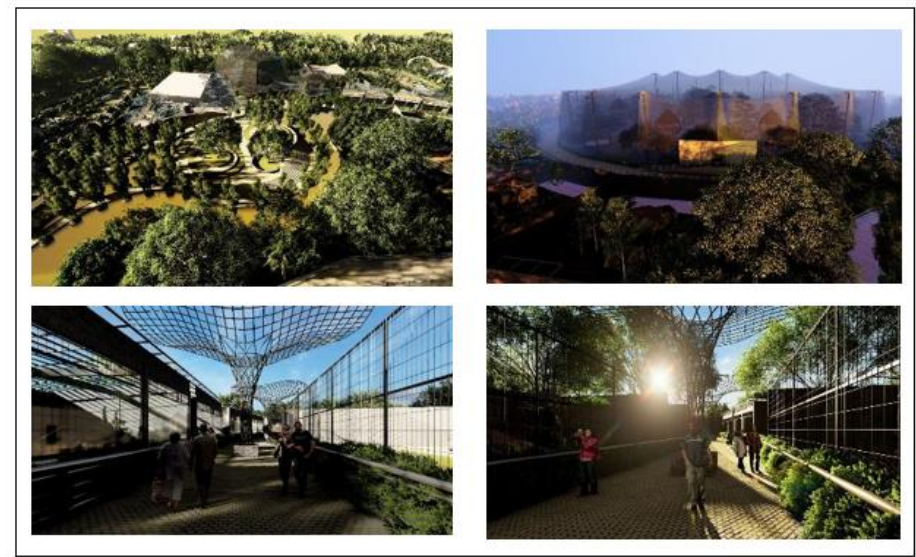

Gambar 29. Suasana Eksterior Kawasan

Sumber: Penulis, 2020

\section{Kesimpulan}

Taman Satwa Kota Pontianak hadir dengan tujuan dapat mewadahi konservasi satwa endemik Kalimantan Barat di Kota Pontianak selain itu juga sebagai sarana rekreasi/wisata bagi masyarakat, sarana edukasi dan penelitian satwa bagi lembaga terkait. Konsep di dalam perancangan ini mengacu kepada bagaimana memelihara satwa di dalam kandang namun tetap memberikan ruang gerak bagi satwa menunjukkan prilaku pada habitat alaminya namun tetap mempertimbangkan keamanan dan kenyamanan bagi satwa dan pengunjung yang berkunjung.

\section{Ucapan Terima Kasih}

Ucapan terima kasih disampaikan kepada Bapak Tri Wibowo Caesariadi, ST, MT, selaku dosen pembimbing utama, Bapak Yudi Purnomo, ST, MT selaku dosen pembimbing pendamping, serta kepada seluruh dosen dan staf Program Studi Arsitektur Universitas Tanjungpura.

\section{Daftar Acuan}

Anwar, T. (2018, May 22). Suhu Aspal saat Penghamparan. Retrieved from: https://aspalmixingplan.blogspot.com BSP Guard. (2017, November 27). Mengenal Jenis Alat Pemadam Kebakaran dan Fungsinya. Retrieved from: https://www.bspguard.co.id

CITES. (2020, January 20). Status Konservasi Satwa. Retrieved from https://www.cites.org

IUCN Red List. (2020, Jan 18). Diagram Status Konservasi Satwa. Retrieved from https://www.iucnredlist.org

Kementerian Kehutanan Republik Indonesia. (2012). Peraturan Menteri Kehutanan Republik Indonesia No. P.31/Menhut-II/2012 Tentang Lembaga Konservasi. Jakarta: Kementerian Kehutanan Republik Indonesia

Kementerian Lingkungan Hidup dan Kehutanan Republik Indonesia. (2018). PERMENLHK No. P.20/ MENLHK/ SETJEN/ KUM.1/ 6/ 2018 Tentang Jenis Tumbuhan dan Satwa Yang Dilindungi. Jakarta: Kementerian Lingkungan Hidup dan Kehutanan Republik Indonesia

Mehta, R. (2018), Design Guidelines for Zoos. New Delhi; Central Zoo Authority

Neufert, E. (2002), Data Arsitek, Jakarta; Erlangga

Nuraini, C. (2010). Metode Perancangan Arsitektur. Bandung: Karya Putra Darwati

Pemerintah Daerah Kota Pontianak. (2013). Peraturan Daerah Kota Pontianak No. 2 Tahun 2013 Tentang Rencana Tata Ruang Wilayah Kota Pontianak Tahun 2013-2033. Pontianak: Pemerintah Daerah Kota Pontianak

Pemerintah Daerah Kota Pontianak. (2014). Peraturan Daerah Provinsi Kalimantan Barat No. 10 Tahun 2014 Tentang Rencana Tata Ruang Wilayah Provinsi Kalimantan Barat Tahun 2014-2034. Pontianak: Pemerintah Daerah Kota Pontianak

Ramadhan, M. (2020, June 25). Pengertian, Fungsi dan Jenis Turap. Retrieved from: https://www.asdar.id

Rani. (2016, December 5). Grass Block. Retrieved from: https://pavingblockindonesia.wordpress.com 